\title{
SELÊNIO EM UMA PERSPECTIVA GERAL: ASPECTOS AMBIENTAIS E BIOLÓGICOS
}

\section{ARTIGO DE REVISÃO}

ALMEIDA, Jéssica Cristina de ${ }^{1}$

CACURO, Thiago Aguiar ${ }^{2}$

ALMEIDA, Jéssica Cristina de. CACURO, Thiago Aguiar. Selênio em uma perspectiva geral: Aspectos ambientais e biológicos. Revista Científica Multidisciplinar Núcleo do Conhecimento. Ano 04, Ed. 10, Vol. 05, pp. 149-163. Outubro de 2019. ISSN: 2448-0959, Link de acesso: https://www.nucleodoconhecimento.com.br/meio-ambiente/selenio

\section{RESUMO}

Selênio (Se) é um elemento da tabela periódica com número atômico 34 e propriedades que são intermediárias ao enxofre e telúrio. Como um metaloide, ele existe em estado sólido em condições normais de temperatura e pressão. Jöns Jacob Berzelius descobriu o selênio em 1817, mas sua importância só foi evidenciada em 1957 como um micronutriente essencial à maioria dos organismos. A partir desta descoberta, muitos estudos e pesquisas se voltaram à melhor compreensão sobre este elemento e seus efeitos em meio ambiental e biológico. A contaminação do solo por selênio pode levar à intoxicação humana e de várias outras espécies, levando o indivíduo à imunossupressão e possível morte. Este artigo apresenta uma prospecção

1 Doutoranda no Programa de Pós-Graduação em Ciências e Engenharia de Materiais. Faculdade de Ciências, Universidade Estadual Paulista "Julio Mesquita Filho".

2 Doutorando no Programa de Pós-Graduação em Biotecnologia e Monitoramento Ambiental. Departamento de Física Química e Matemática, Universidade Federal de São Carlos. 
do selênio nos aspectos ambientais e biológicos, destacando sua importância, que é pouco relatada.

Palavras-chave: selênio, meio ambiente, selenoproteínas, micronutriente, contaminação.

\section{INTRODUÇÃO}

O Selênio (Se) é um dos 118 elementos químicos atualmente presentes na tabela periódica, pertence à família dos calcogênios e se encontra no grupo 16 possuindo número atômico 34 e massa atômica de 78 u, suas características químicas e físicas, são muito semelhantes às do enxofre e do telúrio (SEIXAS, 2007). Em condições normais de temperatura e pressão (CNTP), este metaloide é encontrado na forma sólida, tendo seu ponto de fusão em $217^{\circ} \mathrm{C}$ e ponto de ebulição em $685^{\circ} \mathrm{C}$ (BOYD, 2011; SEIXAS, 2007). O Selênio pode ser encontrado em diversas formas de oxidação, estas são apresentadas na Tabela 1(SEIXAS, 2007).

Tabela 1. Formas químicas do Selênio encontradas em suas diversas oxidações. Extraído de (SEIXAS, 2007).

\begin{tabular}{|c|c|c|}
\hline Nome & Fórmula & Características \\
\hline Selenetos $\left({ }^{-2}\right)$ & $\mathrm{Se}^{2-}$ & $\begin{array}{l}\text { É encontrado em ambientes redutores, } \\
\text { ex. solos e sedimentos. Forma complexos } \\
\text { metálicos e é altamente imóvel. }\end{array}$ \\
\hline Dimetilseleneto & $\left(\mathrm{CH}_{3}\right)_{2} \mathrm{Se}$ & $\begin{array}{l}\text { Gás formado pelas bactérias e fungos do } \\
\text { solo }\end{array}$ \\
\hline Dimetildiseleneto & $\left(\mathrm{CH}_{3}\right)_{2} \mathrm{Se}_{2}$ & Gás formado pelas plantas \\
\hline $\begin{array}{l}\text { Dimetilselenona/Metil } \\
\text { Metilseleneto }\end{array}$ & $\left(\mathrm{CH}_{3}\right)_{2} \mathrm{SeO}_{2}$ & $\begin{array}{l}\text { Metabólito volátil, possivelmente formado } \\
\text { como um intermediário antese ser } \\
\text { reduzido }\end{array}$ \\
\hline Seleneto de Hidrogênio & $\mathrm{H}_{2} \mathrm{Se}$ & $\begin{array}{l}\text { Gás, instável em ar úmido; decompõe-se } \\
\text { a } \mathrm{Se}^{0} \text { em água }\end{array}$ \\
\hline Selênio elementar $\left({ }^{0}\right)$ & $\mathrm{Se}^{0}$ & Estável em ambientes redutores \\
\hline
\end{tabular}




\begin{tabular}{|c|c|c|}
\hline Selenito $\left({ }^{+4}\right)$ & $\mathrm{SeO}_{3}{ }^{2-}$ & $\begin{array}{l}\text { Forma solúvel, comum em condições } \\
\text { suavemente oxidantes, ex.: solos e } \\
\text { partículas de ar. }\end{array}$ \\
\hline Trimetilselenônio & $\left(\mathrm{CH}_{3}\right)_{3} \mathrm{Se}^{+}$ & $\begin{array}{l}\text { É um importante metabólito urinário da } \\
\text { dieta, torna-se rapidamente não- } \\
\text { disponível devido sua fixação pelas } \\
\text { plantas ou volatilização. }\end{array}$ \\
\hline Ácido Selenoso & $\mathrm{H}_{2} \mathrm{SeO}_{3}$ & $\begin{array}{l}\text { É protonado em condições ácido/neutro. } \\
\text { É facilmente reduzido a Se }{ }^{-} \text {pelo ác. } \\
\text { Ascórbico (vitamina C), ou dióxido de } \\
\text { enxofre em ambientes acidificados por } \\
\text { microrganismos }\end{array}$ \\
\hline Dióxido de Selênio & $\mathrm{SeO}_{2}$ & $\begin{array}{l}\text { Gás formado como subproduto da queima } \\
\text { de combustíveis fósseis (temperatura de } \\
\text { sublimação, } 300^{\circ} \mathrm{C} \text { ). } \\
\text { Comum em solos }\end{array}$ \\
\hline Selenato $\left({ }^{+6}\right)$ & $\begin{array}{l}\mathrm{HSeO}_{3}^{-} \\
\mathrm{SeO}_{4}{ }^{2-}\end{array}$ & $\begin{array}{l}\text { É estável em ambientes oxidados, é muito } \\
\text { móvel em solos, estando prontamente } \\
\text { disponível para as plantas. } \\
\text { Lentamente convertido às formas mais } \\
\text { reduzidas, não é tão fortemente absorvido } \\
\text { como o Se (IV) }\end{array}$ \\
\hline
\end{tabular}

\section{DESCOBERTA}

O selênio, embora possua relatos de existência desde a formação geológica da crosta terrestre, foi descoberto e classificado como um elemento químico em 1817, na Suécia, pelo químico Jöns Jacob Berzelius, que viveu entre os anos de 1779 e 1848 (FARIA, 2015; BOYD, 2011; SEIXAS, 2007). Este, observou durante o preparo de ácido sulfúrico em uma câmara de chumbo, um resíduo avermelhado sendo depositado, tal resíduo, ao ser aquecido, liberava um odor fétido, primeiramente 
acreditou-se que se tratava do telúrio, material que apresenta características muito semelhantes e havia sido nomeado duas décadas antes por Martin Heinrich Klaproth, baseado na palavra tellus vinda do latim com o significado de terra (BOYD, 2011). Ao notar que se tratava de um novo elemento, Berzelius o nomeou, por sua semelhança, de selênio, palavra a qual se deriva do grego selènè, que significa lua (FARIA, 2015; BOYD, 2011; SEIXAS, 2007).

\section{IMPORTÂNCIA}

Há muito tempo relatado como agente tóxico responsável por diversos danos à área agrícola, o selênio pôde deixar de ser visto apenas como um vilão ao ser constatada sua importância, em 1957, quando os pesquisadores Schwarz e Foltz descobriram sua ação protetora à saúde, observada em ratos com necrose hepática e deficiência de vitamina E, e em 1973, quando foi descoberto por Rotruck como micronutriente essencial para a maior parte dos organismos (FARIA, 2015; ALENCAR, 2014; CORTECCI, 2010 ;BORTOLI, 2009; MARCO, 2007; ROCHA, 2007). Dentre os papéis deste composto, podemos citar a prevenção de algumas doenças cardiovasculares e neoplasias, o efeito antioxidante e, ironicamente, a desintoxicação por outros metais potencialmente tóxicos, como o mercúrio, por exemplo (FARIA, 2015; CORTECCI, 2010; BORTOLI, 2009; ROCHA, 2007). Além de que, o selênio faz parte da composição de algumas enzimas, alterando uma série de funções metabólicas (CORTECCI, 2010). Estudos também citam que a obtenção adequada deste metaloide pode reduzir o risco câncer. ${ }^{3}$ Entretanto, este micronutriente precisa ser ministrado com cautela, visto que, tanto a sua falta quanto o seu excesso podem causar danos muito graves à saúde (FARIA, 2015; BOYD, 2011; CORTECCI, 2010; BORTOLI, 2009; ROCHA, 2007; SEIXAS, 2007).

\section{EFEITOS NO ORGANISMO}

Devido a sua essencialidade, assim como sua ambiguidade, pelo comportamento de toxicidade em altos níveis e necessidade em baixos, o selênio passou a ser um importante objeto de estudo, e isto é cada vez mais evidenciado, pois ainda hoje, não 
se sabe muito sobre a exatidão de seus efeitos nos organismos em geral (FARIA, 2015; BOYD, 2011; ROCHA, 2007).

A sua função antioxidante, se relaciona às chamadas selenoproteínas, que atuam reduzindo a produção de espécies reativas de oxigênio, protegendo assim, as macromoléculas e membranas do organismo contra a oxidação. Dentre as selenoproteínas temos a selenoproteínas- $P$, e as glutationas peroxidases, sendo estas, encontradas em todos os tecidos de mamíferos em que existem processos oxidativos e dependem do selênio para manter sua funcionalização (ROCHA, 2007). As selenoproteínas também têm sua contribuição no metabolismo do iodo na glândula da tireoide e no sistema imunológico (CORTECCI, 2010).

A absorção do selênio através da alimentação é a melhor forma de obtenção deste micronutriente (FARIA, 2015; BOYD, 2011; SEIXAS, 2007). Após a ingestão e absorção das diversas formas químicas apontadas anteriormente, o selenito é reduzido a $\mathrm{Se}^{2-}$ pela glutationa peroxidase, ou é oxidado a selenato, espécies orgânicas passam por outros processos dando origem também ao Se ${ }^{2-}$ (CORTECCI, 2010; MARCO, 2007). Após isto, o Se $\mathrm{Se}^{2-}$ sai das células vermelhas do sangue e se liga a albumina, para ser transportado até o fígado, onde é sintetizado um selenoproteínas ou excretado, já o selenato, que é uma molécula maior, permanece no plasma partindo também para o fígado ou sendo excretado na urina (MARCO, 2007; ROCHA, 2007;).

Com relação aos humanos, foram constatadas as quantidades ideais e máximas toleradas de selênio para cada estágio de vida, é possível observar isto na Tabela 2 (BORTOLI, 2009).

Tabela 2. Recomendação de ingestão diária de selênio para cada estágio de vida. Extraído de (BORTOLI, 2009).

\begin{tabular}{|l|l|l|}
\hline Estágio de Vida & \multicolumn{2}{|l|}{ Ingestão Diária $\left(\mu \mathrm{g} \cdot \mathrm{dia}^{-1}\right)$} \\
\hline & Recomendada & Limite Máximo Tolerável \\
\hline 0 a 6 meses & - & 45 \\
\hline 7 a 12 meses & - & 60 \\
\hline
\end{tabular}




\begin{tabular}{|l|l|l|}
\hline 1 a 3 anos & 20 & 90 \\
\hline 4 a 8 anos & 30 & 150 \\
\hline 9 a 13 anos & 40 & 280 \\
\hline >14 anos & 55 & 400 \\
\hline 14 a 50 anos (Gestantes) & 60 & 400 \\
\hline 14 a 50 anos (Lactantes) & 70 & 400 \\
\hline
\end{tabular}

\section{EXCESSO DE SELÊNIO NO ORGANISMO}

O excesso de selênio no organismo, embora raro, causa intoxicação, podendo provocar um quadro de selenose cuja gravidade está diretamente ligada com a forma química do composto ingerido, com o tempo de exposição às doses elevadas, com o estágio de vida e também com o estado nutricional do indivíduo afetado (BORTOLI, 2009; MARCO, 2007). Entre os sintomas da intoxicação humana por selênio podem ser citados a quebra ou perda de unhas e cabelos, problemas gastrointestinais, erupções cutâneas, irritabilidade, fadiga e odor de alho na respiração, podendo haver alterações endócrinas (BORTOLI, 2009). Alguns estudos indicam que o excesso de selênio pode estar também relacionado à diabetes (ZHANG, 2019; ZHOU, 2019; ALENCAR, 2014).

\section{AUSÊNCIA DE SELÊNIO NO ORGANISMO}

Os problemas causados pela ausência de selênio no organismo são, fraqueza muscular, imunossupressão, redução no ganho de peso, infertilidade, aborto e retenção de placenta (FARIA, 2015; CORTECCI, 2010; BORTOLI, 2009). A cardiomiopatia, uma doença relacionada ao músculo cardíaco pela deficiência deste composto, recebeu nome de doença de Keshan, que é o nome de uma cidade na China, onde a doença apareceu pela primeira vez, devastando áreas do sudeste e nordeste do país (MARCO, 2007). Um outro tipo de manifestação da falta do selênio afeta os ossos e as articulações, causando artrite e artrose, a má formação dos mesmos (FARIA, 2015; CORTECCI, 2010; BORTOLI, 2009; MARCO, 2007). 


\section{OUTRAS UTILIZAÇÕES}

Além de seu benefício como micronutriente, o selênio é utilizado para aplicações eletrônicas como células solares, intensificador para fotografias em preto e branco melhorando a durabilidade das imagens, catalizador em reações de desidrogenação, na composição de inseticidas e xampus anticaspa, aditivos pata solo, fabricação de vidros e esmaltes vermelhos, na medicina veterinária, dentre outras aplicações interessantes (MOUTA, 2008).

\section{SELÊNIO NO AMBIENTE}

selênio surgiu na natureza, por processos biogeoquímicos e geofísicos, sendo liberados das estruturas cristalinas das rochas pela ação do intemperismo, porém as ações antropogênicas como processos industriais e agrícolas, acabam por redistribuir o elemento no ambiente (FARIA, 2015; BOYD, 2011; SEIXAS, 2007). A mobilidade e biodisponibilidade do composto dependem de sua concentração no solo, onde pode ser absorvido pelas plantas ou lixiviado aos aquíferos, assim como do estado de oxidação em que se encontra (MOUTA, 2008).

O selênio pode ser encontrado no ambiente em quatro estados de oxidação, , são eles: -II, 0, +IV e +VI, além das formas orgânicas e inorgânicas (SEIXAS, 2007).

No solo, são encontrados especialmente o selenato e o selenito, compostos bastante solúveis em água, porém tóxicos no ambiente mesmo em concentrações baixas, também são encontrados, porém em menor quantidade, o selênio elementar, que é insolúvel em água e não apresenta riscos aos sistemas biológicos, e sua forma orgânica, que é altamente biodisponível para organismos (FARIA, 2015; MOUTA, 2008; SEIXAS, 2007).

Em regiões de alta umidade e/ou de solos com pH baixo o selenito se mostra predominante, porém sob condições de neutralidade ou pH alto, este tende a se oxidar para a forma de selenato (MOUTA, 2008) Os selenetos são espécies bastante tóxicas e reativas, entretanto são rapidamente oxidados a selênio elementar no ambiente e a 
forma inorgânica do selênio pode se transformar em organometálicos através atividade bacteriana (SEIXAS 2007). Alguns de seus compostos são voláteis, facilitando sua distribuição no ambiente (FARIA, 2015; BOYD, 2011; SEIXAS, 2007).

No sistema aquático, o ciclo biogeoquímico do selênio se assemelha ao do enxofre, sendo que, ao entrar neste ecossistema, o selênio pode ser absorvido ou ingerido pelos organismos presentes, pode se ligar ou complexar ao material particulado ou à superfície dos sedimentos, ou então, pode permanecer livre em solução, estes processos são observados na Figura 1 (SEIXAS, 2007; FOSTER, 1996).

Figura 1. Ciclo do selênio no ecossistema aquático.

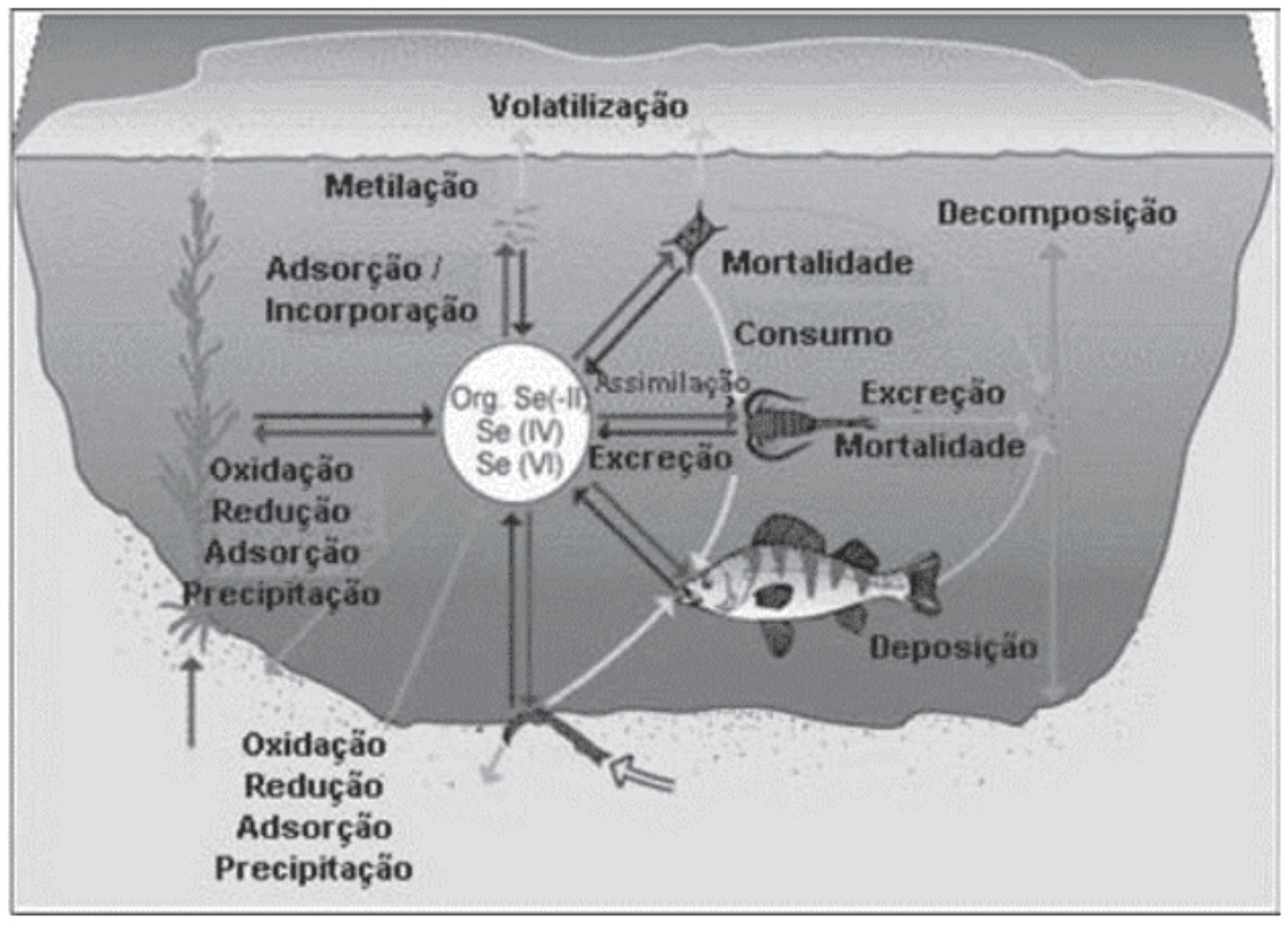

Extraído de (SEIXAS, 2007).

Estudos mostram que $90 \%$ do selênio presente no sistema aquático encontra-se nos sedimentos, e é ciclado por processos físico-químicos e biológicos, permanecendo 
em níveis elevados por anos. O Ciclo do selênio no sedimento é apresentado na Figura 2.

Figura 2. Ciclo do selênio nos sedimentos do ecossistema aquático.

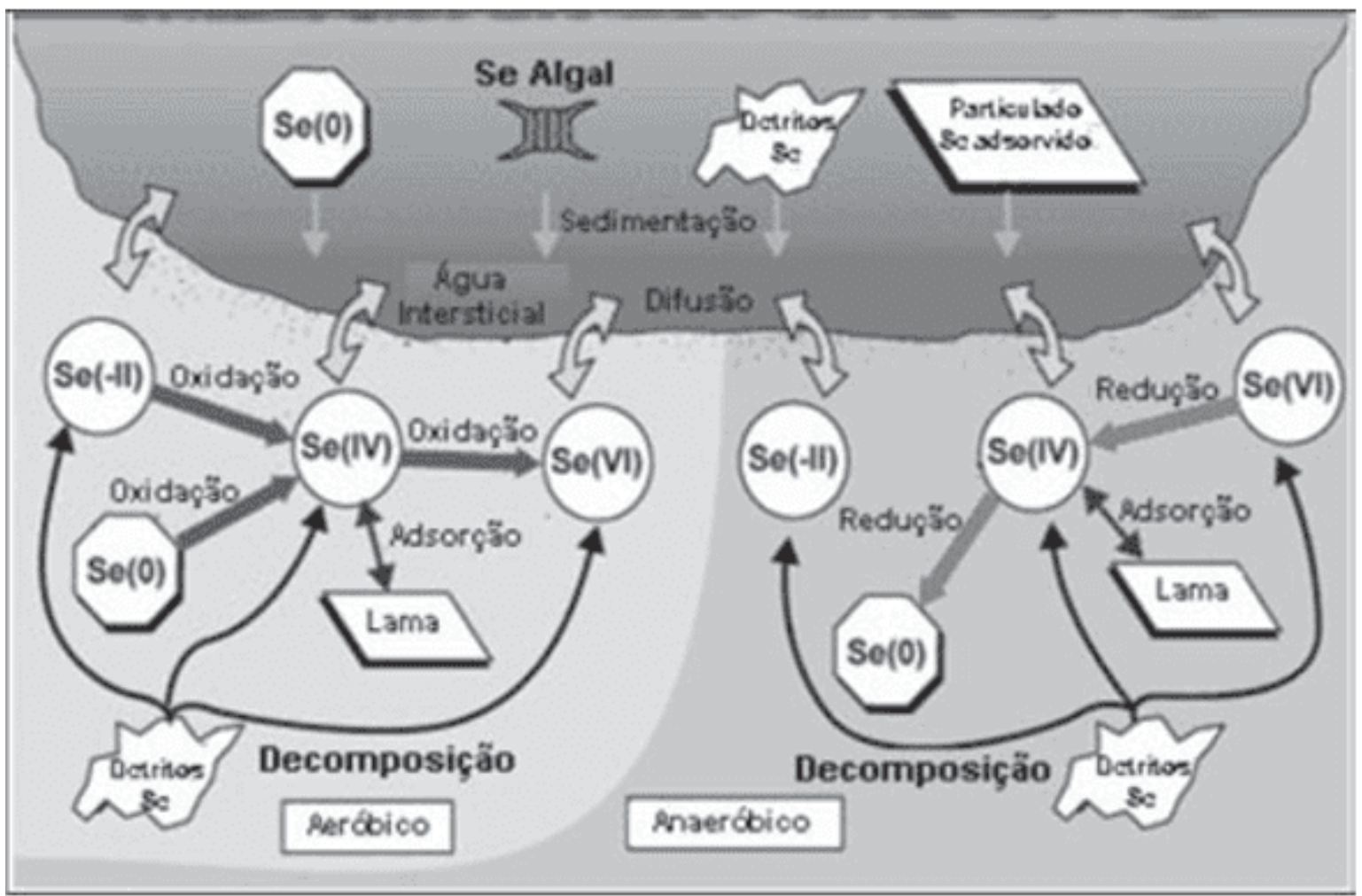

Extraído de (SEIXAS, 2007).

Verificando a geografia, podemos averiguar as chamadas regiões seleníferas, que são áreas onde existe grande incidência de rochas sedimentares, ou seja, regiões de alto teor de selênio no solo, estas áreas podem ser inadequadas ao plantio, já que seus alimentos poderão exceder o limite tolerado de selênio, provocando danos à saúde daqueles que os consomem (FARIA, 2015; BOYD, 2011; CORTECCI, 2010; BORTOLI, 2009; SEIXAS, 2007). Isto é um grande problema ambiental, pois além disso algumas plantas podem acumular este semi metal e ao serem consumidas por animais selvagens ou domésticos, podendo acarretar uma intoxicação causando risco de morte, ou intoxicando àqueles que se alimentarem dos mesmos (FARIA, 2015; BOYD, 2011; CORTECCI, 2010; BORTOLI, 2009; SEIXAS, 2007). Sendo assim, parte 
da crosta terrestre acaba tendo problemas com a carência deste metaloide, enquanto outra parte sofre com o excesso dele (LIN, 2004; ALEIXO, 2000; FOSTER, 1996).

Um exemplo é o que acontece na China, dentro de seu espaço territorial existem áreas seleníferas, causando doenças e matando rebanhos, ao mesmo tempo, também existem áreas que sofrem com a carência deste composto, gerando a chamada doença de Keshan e alterando a calcificação óssea, sistema imunológico, entre outros problemas já mencionados (FARIA, 2015;CORTECCI, 2010; LIN, 2004).

A similaridade entre o selênio e o enxofre causa reações antagônicas no solo, sendo assim é estudada a deposição de materiais que contenham enxofre, como o sulfato de amônio ou gesso sobre o solo contaminado (FARIA, 2015; CORTECCI, 2010). Segundo o pesquisador, desta forma as plantas irão absorver mais enxofre e menos selênio do solo, juntamente, pode ser utilizada a fitoremediação, que envolve o plantio de espécies acumuladoras de selênio, a fim de removê-lo do solo (FARIA, 2015). Uma média das concentrações obtidas através de pesquisas é apresentada na Tabela 3 (VANDERLELIE, 2011).

Tabela 3. Teor de selênio analisado em solo e estimativa de ingestão para diversos países. Extraído de (VANDERLELIE, 2011).

\begin{tabular}{|l|l|l|}
\hline País & Selênio $\left(\mu \mathrm{g} \cdot \mathrm{L}^{-1}\right)$ & Estimativa de consumo $\left(\mu \mathrm{g} \cdot \mathrm{dia}^{-1}\right)$ \\
\hline Egito & 46,9 & 49 \\
\hline Nigéria & 63,5 & - \\
\hline Nova Zelândia (Pré 1983) & 53,9 & 27,4 \\
\hline Grécia & 65,5 & $110-220$ \\
\hline Croácia & 66,8 & 27,3 \\
\hline Finlândia (Pré 1985) & 67,6 & $25-60$ \\
\hline Polônia & 68,3 & $30-40$ \\
\hline Brasil & 72 & 26,3 \\
\hline Itália & 72,8 & 43 \\
\hline Índia & 73 & $28-105$ \\
\hline
\end{tabular}




\begin{tabular}{|c|c|c|}
\hline Dinamarca (1978-1983) & 75,5 & $38-47$ \\
\hline Irlanda & 77,2 & $44-51$ \\
\hline Hungária & 77,4 & $41-90$ \\
\hline Iran-Tabriz & 79 & - \\
\hline Reino Unido (1995-2005) & 79,1 & 29-39 \\
\hline Espanha & 82,3 & 32 \\
\hline Suécia (1987-1993) & 85 & 38 \\
\hline Germânia & 86 & $38-48$ \\
\hline Jamaica & 86 & - \\
\hline Bélgica & 90 & $28-61$ \\
\hline Escócia & 91 & 34,3 \\
\hline Dinamarca (1996-2002) & 94,2 & 68 \\
\hline China-Shanghai & 96,2 & $53-80$ \\
\hline Austrália & 96,7 & $55-87$ \\
\hline Suécia (1992-2006) & 97,6 & 38 \\
\hline México & 100 & $61-73$ \\
\hline Estados Unidos-Nova York & 100.9 & 81 \\
\hline Holanda & 102 & 72 \\
\hline Portugal & 102 & $10-100$ \\
\hline Arábia Saudita & 103 & $75-122$ \\
\hline Finlândia (Pós 1985) & 106,6 & $67-110$ \\
\hline Nova Zelândia (Pós1983) & 113 & $19-80$ \\
\hline Noruega & 113,5 & 77 \\
\hline Canadá-Ontario & 115 & $98-224$ \\
\hline Israel & 119 & 77,3 \\
\hline Cingapura & 119 & - \\
\hline Iran-Jahrom & 119 & - \\
\hline Reino Unido (1970-1988) & 120 & 60 \\
\hline Estados Unidos-MA & 121 & $60-220$ \\
\hline Japão & 122 & $19-180$ \\
\hline Iran - Mashhad & 122,7 & - \\
\hline
\end{tabular}




\begin{tabular}{|l|l|l|}
\hline Canadá-Alberta & 123,5 & $98-224$ \\
\hline Canadá-Montreal & 146 & $98-224$ \\
\hline Tailândia & 146 & $27-75$ \\
\hline Taiwan & 153,2 & 145,2 \\
\hline
\end{tabular}

\section{DETERMINAÇÃO DO SELÊNIO}

A determinação da quantidade de selênio em amostras ambientais como solo e plantas é geralmente efetivada pela técnica de análise denominada de espectrometria de absorção atômica de geração de hidretos (HG AAS) (FOSTER, 1996). Esta é uma técnica de análise muito efetiva, desenvolvida para separar os metais formando hidretos (VANDERLELIE, 2011; ALEIXO, 2000). O atomizador de tubo de quartzo aquecido é particularmente útil para a determinação do selênio, visto que o comprimento de onda em que este elemento absorve energia é abaixo de $200 \mathrm{~nm}$, área a qual, é bastante propensa a ter interferência por técnicas de chama (HINEMAN, 2011; VANDERLELIE, 2011; LIN, 2004; ALEIXO, 2000; FOSTER, 1996). A técnica de HG AAS pode melhorar os limites de detecção por um fator de aproximadamente 3000 vezes o limite de detecção por chama, além de possuir menos interferências se comparada à técnica de absorção atômica por forno de grafite (VANDERLELIE, 2011; FERREIRA, 2002). O funcionamento do equipamento segue descrito na Figura 3 (HENEMAN, 2011). 
Figura 3. Funcionamento de um HG AAS com atomizador de tubo de quartzo.

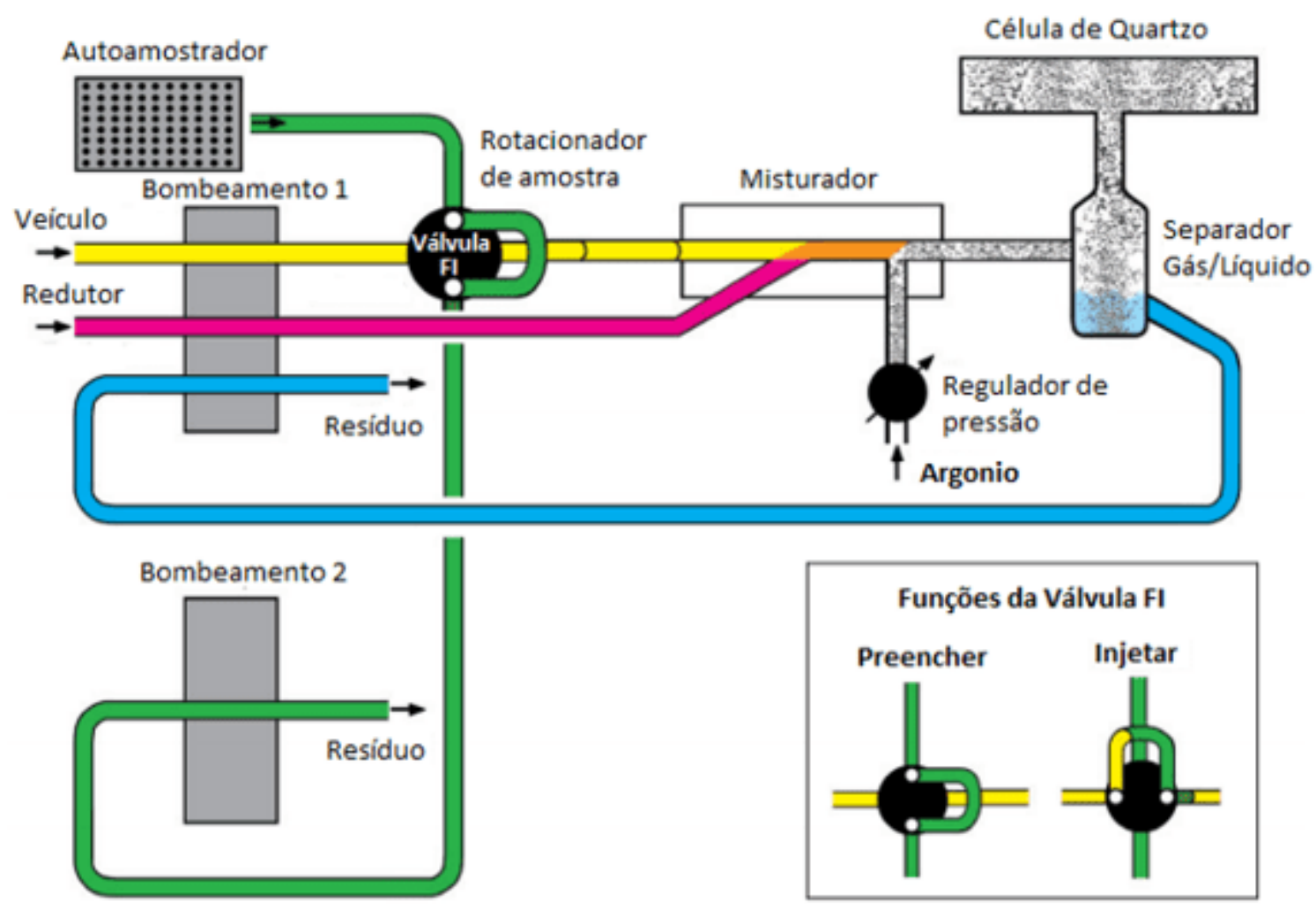

Extraído de: (HINEMAN, 2011).

$\mathrm{Na}$ imagem, é possível identificar o auto mostrador, onde é colocada a amostra a ser analisada, a mesma segue até a válvula FI que, quando acionada, injeta-a junto ao veículo previamente bombeado (HINEMAN, 2011; FOSTER, 1996). No misturador, a amostra junto ao veículo é misturada à solução redutora, borohidreto de sódio, gerando uma reação de redução e formando assim os Selênio hidretos característicos desta técnica, resultando na separação em duas fases vapor com analito e o redutor utilizado (HINEMAN, 2011; FOSTER, 1996). O fluxo de argônio é adicionado a essa mistura, carregando a parte gasosa com ele, passando então por um separador gás/líquido, onde apenas a parte gasosa seguirá para a célula de quartzo para ser atomizada, enquanto a parte líquida se torna resíduo. A célula de quartzo, aquecida a 900ํㅡ decompondo os hidretos e atomizando o selênio (HINEMAN, 2011; FOSTER, 1996). 
Selênio é obtido pelos seres humanos através da alimentação, sendo assim, uma dieta balanceada é de grande importância (FARIA, 2015, BOYD, 2011, SEIXAS, 2007). Como a absorção do selênio no cultivo é dependente da concentração presente no solo, os alimentos cultivados em áreas de replantio apresentarão uma quantidade reduzida do composto, visto que sua disponibilidade no solo foi depreciada pelo cultivo anterior. Embora existam diversos estudos apontando para os benefícios do selênio às plantas, ele não é um elemento essencial ao seu desenvolvimento, sendo assim, não é reposto ao solo pelos agricultores e consecutivamente, chegam à nossa dieta em proporções inadequadas (FARIA, 2015; SEIXAS, 2007; FOSTER, 1996). É possível observar a diferente concentração de selênio nos alimentos através da Tabela 4 (FERREIRA, 2002).

Tabela 4. Teor de selênio em diferentes alimentos. Extraído de (FERREIRA, 2002).

\begin{tabular}{|c|c|c|c|}
\hline Alimentos & $\begin{array}{ll}\text { Teor Médio de } & \text { Se } \\
\text { (mg.100g-1 } & \text { de } \\
\text { alimento cru) } & \end{array}$ & Alimentos & $\begin{array}{ll}\text { Teor Médio de } & \text { Se } \\
(\mathrm{mg} .100 \mathrm{~g}-1 & \text { de } \\
\text { alimento cru }) & \end{array}$ \\
\hline Feijão & 1,0 & Abacate & 0,2 \\
\hline Arroz polido & 0,8 & Abacaxi & 0,0 \\
\hline Farinha de trigo & 5,6 & $\begin{array}{l}\text { Ameixa } \\
\text { seca }\end{array}$ & 0,6 \\
\hline $\begin{array}{l}\text { Farinha de } \\
\text { mandioca }\end{array}$ & 1,6 & $\begin{array}{l}\text { Banana da } \\
\text { terra }\end{array}$ & 0,3 \\
\hline Fubá de milho & 3,4 & $\begin{array}{l}\text { Banana } \\
\text { ouro }\end{array}$ & 0,0 \\
\hline $\begin{array}{l}\text { Farinha } \quad \text { láctea } \\
\text { Nestlé }{ }^{\circledR}\end{array}$ & 2,5 & $\begin{array}{l}\text { Banana } \\
\text { prata }\end{array}$ & 0,1 \\
\hline $\begin{array}{lll}\text { Milho verde in } \\
\text { natura }\end{array}$ & 0,5 & Caqui & 0,2 \\
\hline $\begin{array}{l}\text { Milho verde em } \\
\text { conserva }\end{array}$ & 0,0 & $\begin{array}{l}\text { Goiaba } \\
\text { vermelha }\end{array}$ & 0,4 \\
\hline
\end{tabular}




\begin{tabular}{|l|l|l|l|}
\hline $\begin{array}{l}\text { Alimento } \\
\text { achocolatado } \\
\text { Nescau® }\end{array}$ & 2,7 & Kiwi & 0,1 \\
\hline $\begin{array}{l}\text { Biscoito cream } \\
\text { cracker }\end{array}$ & 6,4 & Laranja & 0,3 \\
\hline $\begin{array}{l}\text { Biscoito de } \\
\text { maisena }\end{array}$ & 4,8 & $\begin{array}{l}\text { Maçã } \\
\text { Argentina }\end{array}$ & 0,1 \\
\hline $\begin{array}{l}\text { Pão francês } \\
\text { Pão de leite doce }\end{array}$ & 5,5 & $\begin{array}{l}\text { Maçã } \\
\text { brasileira }\end{array}$ & 0,1 \\
\hline $\begin{array}{l}\text { Macarrão cru } \\
\text { Macarrão cozido }\end{array}$ & $\begin{array}{l}\text { Mamão } \\
\text { papaia }\end{array}$ & 0,3 \\
\hline
\end{tabular}

Embora não mencionado na tabela, a castanha do Pará é considerada um dos alimentos mais ricos em selênio, aproximadamente $55 \mu \mathrm{g}$, suprindo a dieta diária adequada (FARIA, 2015).

Além da diferença nos teores de selênio para os diferentes alimentos também é possível observar a variação dos mesmos alimentos nos diferentes países, isso se deve ao tratamento aplicado a cada alimento bem como o teor do elemento presente em solo. Um exemplo disso pode ser observado na Tabela 5 (BORTOLI, 2009).

Tabela 5. Teor de selênio em diferentes alimentos. Extraído de (BORTOLI, 2009).

\begin{tabular}{|l|l|l|}
\hline \multirow{2}{*}{ Alimento } & \multicolumn{2}{|l|}{ Teor médio de selênio $(\mu \mathrm{g} / 100 \mathrm{~g})$} \\
\cline { 2 - 3 } & Estados Unidos & Brasil \\
\hline Filé mignon & 35,1 & 5,2 \\
\hline Fígado bovino & 39,7 & 7,3 \\
\hline Coxa de frango & 13,5 & 12 \\
\hline Sobrecoxa de frango & 17,3 & 6,4 \\
\hline
\end{tabular}




\begin{tabular}{|l|l|l|}
\hline Peito de frango & 24,7 & 8,9 \\
\hline Presunto & 17,4 & 7,2 \\
\hline Ovo de galinha inteiro & 31,7 & 15 \\
\hline logurte & 2,2 & 1,7 \\
\hline Leite desnatado & 3,3 & 2,6 \\
\hline Leite integral & 3,7 & 1,9 \\
\hline Feijão preto & 3,2 & 11,9 \\
\hline Arroz polido & 9,3 & 1,9 \\
\hline Farinha de trigo & 33,9 & 6,4 \\
\hline Pão francês & 27,1 & 7,3 \\
\hline Macarrão cozido & 26,4 & 2,3 \\
\hline
\end{tabular}

Devido aos baixos índices do micronutriente em alimentos, existem estudos voltados para a incrementação de selênio na dieta dos animais de corte, a fim de que além de melhorar o seu desenvolvimento, aumente o teor deste micronutriente na dieta dos consumidores (MAETENS, 2015; BOIAGO, 2006; DAHLKE, 2005).

\section{CONCLUSÃO}

O selênio é micronutriente essencial, dentro de um intervalo de concentração estreito onde, sua carência pode ser quase tão grave quanto seu excesso no organismo, faz deste elemento um bom objeto de pesquisa. $O$ trabalho relacionou a parte nutricional de diversos países e alimentos, verificando que dentre tantos contendo selênio, o mais indicado à dieta humana seria a castanha do pará, ou também chamada de castanha do brasil. A radicalidade dos efeitos das áreas seleníferas gerando casos de intoxicação e seu contraste, as áreas pobres em selênio, gerando queda de imunidade e problemas ósseos e musculares puderam ser também evidenciados. O selênio, sendo um elemento químico potencialmente tóxico e de grande importância biológica, ainda precisa de muito estudo para ser de fato revelado, assim como seus métodos de remediação às áreas seleníferas ainda não são conclusivos. 


\section{REFERÊNCIAS}

ALEIXO, Poliana C. et al. Determinação direta de selênio em água de coco e em leite de coco utilizando espectrometria de absorção atômica com atomização eletrotérmica em forno de grafite. Química Nova, v. 23, n. 3, p. 310-312, 2000.

ALENCAR, Luciane Luca de. Estudo dos polimorfismos Pro198Leu no gene da glutationa peroxidase 1 e-617C/A no gene do fator de transcrição Nrf2 com relação ao estresse oxidativo e ao estado nutricional relativo ao selênio de pacientes com diabetes mellitus tipo 1. 2014

BOIAGO, Marcel Manente. Características produtivas e qualitativas da carne de frangos alimentados com diferentes concentrações e fontes de selênio. 2006.

BORTOLI, Maritsa Carla de. Avaliação dos níveis sanguíneos do hormônio tireoidiano ativo (T3) e do estado nutricional relativo ao selênio de mulheres residentes em área de exposição ao mercúrio. 2009.

BOYD, Russell. Selenium stories. Nature chemistry, v. 3, n. 7, p. 570, 2011.

CORTECCI, G.; Geologia e saúde, Geomedicinana 2010, disponível em http://www.cprm.gov.br/publique/media/geosaude.pdf acessada em Agosto de 2016.

DAHLKE, F. et al. Avaliação de diferentes fontes e níveis de selênio para frangos de corte em diferentes temperaturas. Archives of Veterinary Science, v. 10, n. 1, 2005.

FARIA, Letícia A.; KARP, Felippe H. S.; Selênio: um elemento essencial ao homem e aos animais e benéfico às plantas, Informações Agronômicas 2015, 144.

FERREIRA, Karla Silva et al. Concentrações de selênio em alimentos consumidos no Brasil. Revista Panamericana de Salud Pública, v. 11, p. 172-177, 2002.

FOSTER, L. H.; SUMAR, S. Hydride generation atomic absorption spectrometric (HGAAS) determination of selenium in term and preterm infant formulae available in the United Kingdom. Food Chemistry, v. 55, n. 3, p. 293-298, 1996. 
HINEMAN, A. Determination of as, se and hg in waters by hydride generation/cold vapor atomic absorption spectroscopy. PerkinElmer: Canada, 2011.

LIN, Nian-Feng; TANG, Jie; BIAN, Jian-Min. Geochemical environment and health problems in China. Environmental geochemistry and health, v. 26, n. 1, p. 81-88, 2004.

MARCO, Katia Cristina de. Avaliação da exposição ao metilmercúrio e dieta rica em selênio sobre os níveis de óxido nítrico na população da região amazônica. 2007.

MARTENS, Irland BG et al. Selenium status in preschool children receiving a Brazil nut-enriched diet. Nutrition, v. 31, n. 11-12, p. 1339-1343, 2015.

MOUTA, Ernesto Rinaldi et al. Adsorção de selênio em Latossolos. Revista Brasileira de Ciência do Solo, v. 32, n. 3, p. 1033-1041, 2008

ROCHA, Ariana Vieira. Status de selênio de uma população residente em área de risco de contaminação por mercúrio. Influência de polimorfismos e ação sobre o estresse oxidativo. 2015. Tese de Doutorado. Universidade de São Paulo.7.Marco, K. C.; Dissertação de Mestrado, Faculdade de Ciências Farmacêuticas de Ribeirão Preto, Brasil, 2007.

SEIXAS, Tércia G.; DO A KEHRIG, Helena. O selênio no meio ambiente. Oecologia Brasiliensis, v. 11, n. 2, p. 264-276, 2007.

SIEPRAWSKA, Apolonia; KORNAŚ, Andrzej; FILEK, Maria. Involvement of selenium in protective mechanisms of plants under environmental stress conditionsreview. Acta Biologica Cracoviensia s. Botanica, v. 57, n. 1, p. 9-20, 2015.

VANDERLELIE, Jessica; PERKINS, A. V. A. Selenium and preeclampsia: a global perspective. Pregnancy Hypertension: An International Journal of Women's Cardiovascular Health, v. 1, n. 3-4, p. 213-224, 2011. 
ZHANG, Qianqian et al. Selenium Levels in Community Dwellers with Type 2 Diabetes Mellitus. Biological trace element research, p. 1-9, 2019.

ZHOU, Qi et al. Serum and Urinary Selenium Status in Patients with the Pre-diabetes and Diabetes in Northeast China. Biological trace element research, v. 191, n. 1, p. 61-69, 2019.

Enviado: Setembro, 2019.

Aprovado: Outubro, 2019. 